\title{
Exploring school and home food environments: perceptions of 8-10-year-olds and their parents in Newcastle upon Tyne, UK
}

\author{
Laura Briggs ${ }^{1,2}$ and Amelia A Lake ${ }^{1,3, *}$ \\ ${ }^{1}$ Human Nutrition Research Centre, Institute of Health and Society, Newcastle University, Newcastle upon Tyne, \\ UK: ${ }^{2}$ Central London Community Healthcare NHS Trust, London, UK: ${ }^{3}$ Centre for Public Policy and Health, \\ School of Medicine and Health, Wolfson Research Institute, Durham University, Stockton-on-Tees TS17 6BH, UK
}

Submitted 8 October 2010: Accepted 19 June 2011: First published online 23 August 2011

\begin{abstract}
Objective: To use an innovative mixed-method approach to analyse and describe 8-10-year-olds' home and school food environments.

Design: A mixed-method approach to collect qualitative and quantitative data was used, in which pupils took photographs over four days to record their food intake and food environment. The photographs were discussed in focus groups. A combination of lunchtime observations and questionnaires completed by parents were used to build up a picture of the children's home and school food environments. Setting: A primary school in a suburb of Newcastle upon Tyne, UK.

Subjects: Twenty-seven children aged 8-10 years consented to take part in the study. Twenty-four returned cameras, and eighteen parents completed questionnaires.

Results: Photographs illustrated a range of locations throughout the home where children consumed food. Children's photographs revealed they ate less often with family and more often in front of the television than reported in parental questionnaires. Emergent themes during focus group discussions revealed a strong preference for packed lunches and dissatisfaction with school dinners. In this small sample, children's eating habits and preferences showed few associations with either gender or the deprivation level of the area in which they lived.

Conclusions: The children's home food environments showed a great deal of variation, with parents being key moderators of food availability and consumption. While the school's food provisions met national nutritional standards, the social aspects of having a packed lunch appeared to be a positive aspect of eating at school.
\end{abstract}

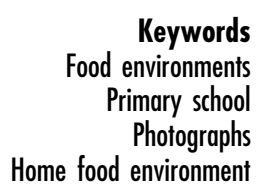

In the North East of England, the prevalence of overweight and obesity in children is significantly higher than the national average ${ }^{(1)}$. Recent data from the National Child Measurement Programme (2007/2008) regarding children aged 10-11 years from the North East indicated that $14.7 \%$ were overweight and $20 \cdot 4 \%$ were obese, compared with the national averages of $14 \cdot 3 \%$ and $18 \cdot 3 \%$, respectively. Individual food choices and behaviours are influenced by physical, social, cultural, economic and policy factors, and, as with adiposity, food behaviour established in early life has been shown to track into adulthood $^{(2,3)}$.

The environment's influence on individual behaviours is considered to be a driving force in the obesity pandemic $^{(4)}$. Food availability and accessibility are key features of the obesogenic environment ${ }^{(4-7)}$. The multifactorial, complex relationship of different social and physical influences on children's eating habits has been explored ${ }^{(8)}$, yet little is known about how food availability and obesity in children interact.
The home food environment encompasses a range of factors that can affect the type and quantity of foods that a child consumes ${ }^{(\Theta, 10)}$. Establishing whether certain foods are in places known and accessible to the child is essential in building up a picture of the home food environment ${ }^{(11)}$. Previous studies have had varying amounts of success when attempting to explore the complex relationships between different features of the home food environment and food behaviours. Campbell et al. ${ }^{(12)}$ found that mothers' eating behaviours had a strong influence on their adolescent children, while Bryant et al. ${ }^{(13)}$ observed, through a combination of telephone interview and home visits by researchers, that the likelihood of error in self-reporting of the home food environment by parents was high.

Socio-economic status may also influence a child's eating behaviours ${ }^{(10)}$; children from families with a lower income appeared less likely to be discouraged from eating sweets by their parents and more likely to skip breakfast and eat meals in front of the television than children from families with a higher income ${ }^{(10)}$. 
The school environment has a daily influence on what children eat, as children consume at least one meal and some snacks here. Additionally, teachers and peers can influence what children eat and how they feel about food ${ }^{(14)}$. Food policy has been found to be very effective in promoting healthy eating at school ${ }^{(15)}$. In the UK, since September 2007, the School Food Trust guidelines ${ }^{(16)}$ have outlined the standards for school lunches that all primary and secondary schools must adhere to. This is monitored regularly by Oftsed, the Office for Standards in Education, Children's Services and Skills.

Although few children are thought to take personal responsibility for their health ${ }^{(17)}$, understanding the influences on children's dietary attitudes and preferences could be extremely useful in designing interventions to encourage healthy eating ${ }^{(18)}$.

The aim of the present study was to investigate the home and school food environment of Year 4 pupils (8-10 years), from the children's perspectives as well as their parents', by exploring their food environment using cameras and focus group discussions. Questionnaires completed by parents provided an indication of the parents' perceptions of the children's home food environment. Food provisions at school were evaluated in relation to current School Food Trust guidelines ${ }^{(16)}$.

\section{Methods}

\section{Background}

The primary school wherein the study was conducted consisted of 309 pupils, and was located within the Ouseburn ward of Newcastle upon Tyne, North East England. Ouseburn is a large and very diverse ward characterised by a mix of Victorian flats and terraces ${ }^{(19)}$. It includes five major student accommodations and numerous open green spaces, including parks. The postcode area of the school has an Index of Multiple Deprivation (IMD) ${ }^{(20)}$ score of 8679 , putting it just outside the $25 \%$ most deprived wards in the UK. IMD is a summary measure of area-level deprivation that combines weighted scores in seven deprivation domains ${ }^{(20)}$. These domains are: (i) income deprivation; (ii) employment deprivation; (iii) health deprivation and disability; (iv) education, skills and training deprivation; (v) barriers to housing and services; (vi) living environment deprivation; and (vii) crime. The IMD rank was identified for each of the participant's Lower Super Output Areas from their home postcode. These ranks were divided into sample quartiles, where a rank of 1 was 'most deprived' and 4 was 'least deprived'. The attainment level of the school was based on Key Stage 2 SATs results for 2008. These are Standard Aptitude Tests sat by children in their last year of primary school (aged 10-11) to assess their progress against other children of their age. These were only slightly below the average SATs results for England.

Since 2007 the school had been running a range of health interventions for its pupils, including the transformation of the outside space into a learning environment, with new equipment for play and an allotment garden where vegetables are grown and tasted. An evaluation of this intervention was not possible as baseline data had not been collected. However, the school was keen to explore how environments within and outside the school may influence the health-related behaviours of its pupils.

\section{Recruitment}

Following discussions with the head teacher and teachers, the study was verbally explained to the pupils in class. Year 4 pupils were selected for the present study because they were of similar age to children who took part in a study by Pearce et al. ${ }^{(21)}$, which used a similar mixed-method approach with disposable cameras, and to children taking part in the Gateshead Millennium Baby Study, with whom it was originally intended to compare home food environment data ${ }^{(11,12,22)}$. Participation was by informed consent; the parents of all forty-eight children within the year were sent a recruitment letter and consent form, and informed that they could opt out of the study at any time without giving a reason.

\section{Data collection}

A mixed-method approach was adopted to collect information on the children's home and school food environments. In terms of understanding diet-related behaviours, using this approach offers a 'deeper insight ${ }^{(23)}$ and helps to understand 'the meanings, the concepts and symbols',(24) relating to dietary behaviours. Using both qualitative and quantitative methods adds 'breadth and depth to research' and can capture the socio-cultural influences on food choice and dietary behaviours ${ }^{(25)}$.

\section{Gaining the children's perspectives}

Each child was provided with a disposable camera with twenty-four exposures (selected to be adequate for the time period, with six or seven pictures per day) and asked to take pictures over four days (Weds, Thurs, Fri, Sat) of everything they ate and drank on these days, where they ate it (e.g. home, school, restaurant) and who they ate it with (e.g. friends, family), similar to a previous study by Pearce $e t a l{ }^{(21)}$. A short instruction sheet with examples of the sort of pictures required was given with the camera (instruction sheet is available on request from the corresponding author). After the photographs had been processed, photographs for each child were attached, in chronological order, onto A3 sheets of paper. Two researchers trained in qualitative techniques conducted six focus groups with groups of three to five children (only those who used and returned a camera) to discuss their photographs.

Focus group discussions were completed using a structured interview proforma generated following a review of the available literature and focused on four key themes: (i) the children's food environment; (ii) food intake; 
(iii) obtaining food; and (iv) social aspects of food consumption. Initially each child was asked specific questions about their photographs in order to clarify the foods they had consumed, where they were consumed, and with whom. This helped to generate further discussions about how and why they made their food choices and about their food environment at home and at school. The focus groups were recorded and transcribed. Quotes within the Results section are labelled with the child's gender and ID number (e.g. F1) as well as their IMD deprivation rank from 1 (most deprived) to 4 (least deprived).

\section{Gaining the parents' perspectives: the home}

food environment

An existing Home Food Environment Questionnaire (HFEQ) for use in the UK with older adolescents developed by Lake et al. ${ }^{(26)}$ was adapted using other existing age-relevant questionnaires in order to address all areas of interest for the present study ${ }^{(11,12,22)}$. The result was an eighty-item questionnaire. A 5-point Likert scale was used to obtain information about the frequency of behaviours in the past month, including consumption of breakfast and takeaways, eating locations, access to snacks, fruit and sugary drinks, eating in front of the television, and use of food as a reward. The questionnaire was reviewed by experienced researchers and piloted with researchers and two mothers of similar aged children for its ease of completion, then amended according to their recommendations. These were given to children to take home. Unfortunately, time limitations prevented follow-up of those parents who did not complete the HFEQ.

\section{The school food environment}

An informal observation of the school's dining room was conducted during one lunch service in December 2008 by a researcher, in order to learn more about the school food environment. Copies of the menu (produced by the Local Education Authority) were obtained and evidence of their conformance with each of the School Food Trust's foodbased standards ${ }^{(16)}$ was recorded (e.g. bread provided, water readily available). In addition, a brief discussion with the cook gave more insight into compliance with the set menu.

\section{Analysis}

Analysis of the focus groups identified recurrent themes and importance was established by the frequency with which factors emerged in the discussions ${ }^{(27)}$. Frequency of themes in the photographs was recorded. Responses to the HFEQ questionnaires, which used a Likert scale ('never', 'rarely', sometimes', 'frequently' and 'always'), were quantified as scores of $1-5$, respectively. These, as well as the frequency of themes in photographic evidence, were analysed using the SPSS statistical software package version 15 (SPSS Inc., Chicago, IL, USA). The $\chi^{2}$ test was used to investigate possible associations among the categorical variables (e.g. gender, IMD quartile position and themes emergent from the photographic thematic analysis, home food environment factors).

\section{Etbics}

Ethical approval was obtained from Newcastle University's Research Ethics Committee.

\section{Results}

Twelve boys and twelve girls aged 8-10 years (mean age 9 years) returned used cameras and took part in focus group discussions. There was a large variation in the number of photographs taken per child, as shown in Table 1. No child used all of his/her twenty-four photographic exposures. Eighteen HFEQ completed by parents were returned; the majority $(78 \%, n 14)$ were completed by mothers, with two (11\%) completed by fathers; a further two (11\%) did not specify who had completed it. There were no statistically significant differences between IMD ranking and response rate for returning cameras or parents' completion of the questionnaires, or between the parents' HFEQ responses and gender of the child.

\section{Children's and parents' perspectives}

This section is divided into themes to cross-reference photographic data (Table 1), comments made by the children during focus group discussions and the parents' HFEQ responses that complement these themes. Table 1 summarises the analysis from the photographs taken by the children.

\section{Where children consume food}

Children described eating food and meals in a variety of settings, as illustrated by the quotes below and in photographs:

We were in the sitting room because something really good was on the television and I begged. (F6, IMD 3)

I came from my bed to sit on me mam's bed [to eat breakfast]. Me mam sometimes puts music on. (M24, IMD 2)

Over half of the parents $(56 \%, n$ 10) reported that their children 'always' sat at a table to eat their meals; however, the photographs taken by the children indicated that a higher proportion $(75 \%, n$ 18) ate in either the lounge (fifty-nine photographs) or a bedroom (most commonly the parent's bedroom and while eating breakfast; fifteen photographs). The majority of parents $(83 \%, n 15)$ stated that their child 'always' ate breakfast and most of these $(72 \%, n 13)$ ate it at home rather than on the way to school or at school:

I'm eating with my brother in the sitting room ... I eat in the bedroom before school but in the living room after. (M11, IMD 1) 
Only four parents responded 'never or rarely' to the statement 'My child ate a meal in front of the TV'. When exploring food rules in the focus groups with the children, only three $(12.5 \%)$ were never allowed to watch television at home while eating. Over half the children $(63 \%, n 15)$ presented photographs showing them eating while watching television or using a computer (thirty-two photographs).

Takeaway meals were photographed by seven children, and only one of these children showed evidence of takeaway consumption on more than one occasion (eight photographs). In line with the photographs, almost all parents $(89 \%, n 16)$ reported that their children consumed limited amounts of fast food, although $78 \%$ ( $n$ 14) recorded that they 'sometimes' eat out.

\section{Who children eat with}

The focus group discussions were in agreement with the photographs taken by the children that they ate more often with their siblings (eighty-three photographs, $23 \%$ ) than parents or extended family (twenty-nine photographs, $8 \%$ ). Eight children (33\%) mentioned eating with siblings, while only four (17\%) mentioned eating with their parents:

They'll [Mum and Dad] cook their tea while we [me and my siblings] eat, and [they] eat when we've gone to bed apart from weekends when we watch TV together. (M17, IMD 3)

Usually my dad gets up to make breakfast and I watch TV while [my parents] lie in. (F8, IMD 4)

While most parents $(78 \%, n$ 14) reported that they ate an evening meal with their child four or more times per week, only half ate breakfast with their child as frequently.

Three children (13\%) discussed frequently eating alone; this was even considered to be a treat in some cases, particularly to get away and have 'peace' from younger siblings:

If I help make the tea I earn a prize and I can choose what that is and I choose to eat in my room because I have a computer that plays DVDs. (F19, IMD 4)

In the bedroom, on my bed ... I prefer it a lot more so I can have some peace. (M16, IMD 2)

However, eating alone was seen in few photographs (sixteen photographs, 5\%). The photographs and focus group discussions indicated that the daily life pattern was complex for some children, with food being consumed at the homes of their mothers, fathers and grandparents.

\section{Permission to take food at home}

Fourteen children (58\%) mentioned that, when at home, the only foods they were allowed to eat without requesting permission first were fruit and water:

I can take fruit but I have to ask for crisps or chocolate, my mum would be like 'where's that from, why didn't you ask me?' (F15, IMD 3) 
Parents reported that sugary drinks were more often stored in accessible places (28\% 'frequently' or 'always' where they could be 'seen and easily reached') than highcalorie snacks such as sweets and biscuits (22\% 'frequently' or 'always' where they could be 'seen and easily reached'). However, sugary soft drinks were present in relatively few photographs compared with water, fruit juice and milk (eighteen compared with fifty-seven, Table 1). Questionnaire responses from the parents indicated that fruit and vegetables were stored where they could be 'seen and easily reached'.

\section{Food rewards and praise for eating}

Most parents reported using food to reward good behaviour $(72 \%, n 13)$ or punish bad behaviour $(67 \%, n 12)$. Fourteen parents (78\%) stated that they 'never' rewarded their child for eating fruit or vegetables; however, $50 \%$ $(9 / 18)$ reported that they did praise their child for having consumed fruit or vegetables. Most parents $(67 \%, n 12)$ 'mostly' or 'always' encouraged their child to try things that he/she does not like.

\section{Eating between meals}

Six children (25\%) described having a 'snack' or food after school. One child described a snack as a smaller version of a meal to keep him going:

We come home really cold and have something to warm up, like leek and potato soup; then we watch telly and have our dinner later. (M17, IMD 3)

Other children described snacks as more of a treat:

Yeah, I usually have one [bedtime snack]. That's hot chocolate and rusks. (F15, IMD 3)

Me mam [buys chocolate for us] ... but we're not allowed them until after tea. (F25, IMD 1)

Five children (21\%) mentioned getting snacks on the way to and from school:

If I'm walking home with my mum we stop at a small supermarket corner shop and there's treats and chocolate that you can get there. (M26, IMD 4)

In general, evidence of fruits and vegetables in photographs was compliant with descriptions given by children in the focus group discussions; however, the frequency of fruit and vegetables in photographs varied greatly between respondents:

This is breakfast - porridge and raisins and a kiwi on the side. (F8, IMD 4)

Usually I ask if I can have a banana [after tea] and my mum'll say yes because I eat a lot of fruit. (M17, IMD 3)

\section{Eating at school}

A topic that the children discussed with great enthusiasm was school dinners; however, opinions varied between children:

I like a few of the school dinners but not most so I nearly always have packed lunch. (M26, IMD 4)

I like school dinners because they do ice-cream. (F6, IMD 3)

Many children described having left some or all of the school dinners they photographed because they didn't like them. Comments made about packed lunches were generally positive. Many children mentioned being jealous of other children's lunch boxes, not liking to have the same foods every day, and having school dinners if there was not enough food available in the house to make their packed lunch:

[Another child has] chocolate spread sandwiches and I'm very jealous of him... (F6, IMD 3)

I like school dinner, especially rice pudding. I like having something different every day. (F10, IMD 4)

I normally have packed lunch but occasionally I fancy a change because she gives me the same stuff every day. (M9, IMD 3)

Yeah [I always have packed lunch] except if we've forgotten to shop. (M17, IMD 3)

Packed lunches and school dinners were equal in prominence in photographs (twenty-eight and twentynine respectively, $8 \%$ ). In agreement with this, parent HFEQ responses to the statement 'My child took food to school from home' were quite evenly divided, with six (33\%) parents answering 'never or rarely' and five (28\%) answering 'every day'. The remaining seven parents stated their child took food from home between one and six times per week.

\section{The school dining room environment: rules and breaking rules}

Other themes emerged during the discussion. These included the environment of, and behaviours within, the school dining room, where many children took photographs of their classmates wearing coats and made reference to the dining room being too cold and the need to rush eating:

I try to rush it so I can get out in the heat. It's very cold in the dinner hall, there's no heating. (M2, IMD 3)

Many children enjoyed the 'top table'* feature, but felt that there was often a dash to queue for school dinners in

\footnotetext{
* Particularly well-behaved children are selected by their class teacher to sit at a table at the head of the hall with the head teacher and eat with proper crockery, glasses and metal cutlery, rather than from plastic trays and cups.
} 
order to get a better choice. Four children mentioned swapping or 'trading' packed lunch items, despite a school rule forbidding it due to concerns over food allergies. Foods high in fat or sugar such as chocolate and crisps were most frequently highlighted as being swapped:

That's after I traded ... the sandwich was for the chocolate mini roll and the crisps for the Kit-Kat. He gave me half of this chocolate bread thing for free. (M26, IMD 4)

\section{Weekend v. weekday eating}

Another key topic that emerged from the photographs and discussions with the children was the difference between their eating habits at weekends and on weekdays. Differences included types of food eaten as well as the location where food was consumed and despite expressing a preference for having the same things in packed lunches, they seemed to relish this break from the weekday routine:

On weekdays I have it [supper] downstairs and at weekends I have it in my room. (M1, IMD 1)

We usually have egg stuff [for breakfast at weekends]. (F8, IMD 4)

The focus group discussions revealed that children had a moderate amount of input into the types of food they ate. Many mentioned making some form of contribution to meal planning and preparation, and this concurred with parents' HFEQ responses with regard to acknowledging children's suggestions when planning meals.

\section{Associations with Index of Multiple Deprivation}

There was a statistically significant association between IMD quartile and frequency of evidence of both packed lunches $\left(\chi^{2}=21 \cdot 600, \quad P=0 \cdot 01\right)$ and school dinners $\left(\chi^{2}=18 \cdot 711, \quad P=0.028\right)$ in photographs. The most deprived IMD ranking group had the lowest number of photographs showing packed lunches (one photograph) while the least deprived IMD ranking had the highest number of photographs showing packed lunches (eleven photographs). The opposite was true for school dinners.

The $\chi^{2}$ test indicated that IMD ranking was significantly associated with four responses to HFEQ questions: 'I [parent] praise my child if he/she eats fruit or vegetables' $\left(\chi^{2}=24 \cdot 055, P=0 \cdot 007\right)$; 'My child can have dessert if they finish something they don't like' $\left(\chi^{2}=19 \cdot 000\right.$, $P=0.025)$; 'I [parent] have regularly scheduled meals and snacks with family' $\left(\chi^{2}=19 \cdot 000, P=0 \cdot 025\right)$; and 'I [parent] offer healthy snacks when my child is hungry' $\left(\chi^{2}=22 \cdot 638, P=0 \cdot 004\right)$.

The parents of the children from the two most deprived areas reported that they praised children more frequently for eating fruit and vegetables. One explanation was offered by the handwritten annotations of a parent in the least deprived IMD group, explaining that their child did not require praise or the offer of healthy snacks because they chose to eat fruit, vegetables and healthy snacks of their own accord. Children from the two most deprived areas were also offered healthy snacks and allowed to have dessert if they finished something they did not like much more frequently. Parents of children in the most deprived areas reported having meals and snacks with their families more often.

\section{The school food environment}

The primary school adhered to the Newcastle City Council three-week rotating lunch menu and to the national mandatory School Food Trust standards for school meals ${ }^{(16)}$. These were implemented in September 2007 to improve the nutritional content of school meals, and include eleven food-based and fourteen nutrient-based requirements. During a lunchtime observation and discussions with staff and children it was established that children were permitted to sit where they chose (they were previously separated into packed lunch/school dinner seating areas, but this was abandoned after children switched meals to sit with their friends), and although all school teachers are encouraged to eat lunch sitting with them, not all do. Well-behaved children were selected each week by their teacher to sit at a 'top table' where they eat with proper crockery rather than plastic trays. The focus group data indicated that this was considered both a privilege and treat by the children (see earlier section on school dining room environment).

\section{Discussion}

The present study was an exploratory one to examine children's perspectives of their school and home food environments. Parents provided their perspective of their child's the home food environment.

Parental reporting indicated that most children had easy access and permission to take fruit at home, although there was a range of responses both from parents and children regarding to the storage of, and children's access to, highcalorie snacks and sugary drinks. As would be expected in children of this age, parents were key moderators in the consumption of foods.

The 'packed lunch $v$. school dinner' debate brought to light some key themes: that most children taking packed lunches had the same things every day; that school dinners were generally viewed as less desirable than packed lunches; that having a packed lunch presented a popular opportunity to be involved in 'trading' or food swapping; and that a key factor in the decision to have school dinners was low food availability at home if parents did not have time to shop. A recent study ${ }^{(28)}$ comparing packed lunches with school dinners in 120 primary-school children (6-11 years old) in England reported that packed lunches contained $50 \%$ more $\mathrm{Na}$ and saturated fat and twice the amount of sugar of a school lunch. However, 
packed lunches were significantly higher in $\mathrm{Fe}$ and $\mathrm{Ca}$. While nutritional guidelines exist for school meals, guidelines do not exist for children's packed lunches, although it is recommended that schools set up their own packed lunch policies ${ }^{(16)}$.

Children spoke at length about the various places where they consumed food and who they consumed food with. Many described eating in different places depending on the time of day. Breakfast settings were the most varied and included the sitting room, kitchen and bedroom. Siblings were described as company during meals twice as frequently as parents, particularly during the week and at breakfast time, with other children describing their parents being in the same room but doing other things (e.g. washing up). However, parents reported that they ate with their children much more frequently than this, highlighting the possibility of over- or under-reporting. Some children expressed a preference for eating alone, often in front of a computer or while watching television.

Watching television was often described as a social occasion for the whole family by the children, and over half of the children presented photographs showing television viewing while eating. Internationally young people are known to watch significant amounts of television $^{(29)}$ and other studies have observed that a significant portion of children's daily food intake is consumed while watching television ${ }^{(30)}$. Television viewing has consistently been linked to a raised adiposity in children ${ }^{(31)}$. Pre-school children who watch more television are more likely to be overweight ${ }^{(32)}$. In the small sample of children in the present study, the photo diaries offered an insight to the fact that, for many children, television viewing or computer use was at the same time as food consumption. Furthermore, very few parents appeared to limit television watching according to reporting through the HFEQ.

Although parental responses to the HFEQ, the $4 \mathrm{~d}$ photo diaries and statements made by children during focus group discussions gave many coherent messages (the consumption of fruit, vegetables, snacks, packed lunches, school dinners and takeaway foods; television or computer use while eating), themes which showed the greatest degree of conflict between parents and children were eating at a table and eating evening meals with parents. Parents' reporting conveyed a picture of a family eating together around a table. However, many more children than parents reported, and in photographs were seen, eating meals or snacks while seated on a sofa (with or without a tray), on the floor or on a bed. Murcott ${ }^{(33)}$ suggests that the concept of sitting round a table as a coherent family unit is a middle-class family 'ideal' to which many aspire and to which past generations may also have aspired. It may be a lament of the 20th and 21st centuries that family meals are declining; historically, however, in upper middle-class families, children rarely ate with their parents ${ }^{(33)}$.

Despite the small sample size, IMD quartile ranking illustrated some interesting associations. The evidence that school meal consumption was higher in photographs from children living in more deprived areas suggests a link between deprivation level and school meals. The uptake of free school meals in the UK has been used as a proxy measure for deprivation ${ }^{(34)}$; however, in the present study we did not record whether or not children received free school meals. Associations were observed between home IMD scores and a number of parental questionnaire responses. Children from more deprived areas were more often offered healthy snacks, praised for fruit and vegetable consumption, and rewarded for eating foods they disliked with dessert compared with children living in less deprived areas. Hupkens et al. ${ }^{(35)}$ examined food rules imposed by mothers from different socioeconomic groups. A higher priority was given to health by mothers with higher socio-economic status, who were also more restrictive, while mothers with lower socioeconomic status were more concerned with children's food preferences. While there is a complex interaction between food choices and economic status ${ }^{(36,37)}$, the results reported in our exploratory work are in contrast to previously published findings summarised by Rosenkranz and Dzewaltowski ${ }^{(10)}$.

A recent study by Pearce et al. ${ }^{(21)}$, exploring environmental influences on the diets of children aged 9-11 years in north London, used similar mixed methods to the present study. Their findings highlighted the key role of parents as mediators of children's food intake. Although parents have a large degree of control over their child's food habits by taking responsibility for food availability and access, the role of the home food environment as a 'substantial'(10) environment in which children learn about food habits and form their behaviours needs to be better understood. In the present study, the children appeared to have a limited level of input with regard to foods in their packed lunches, but more input into their evening meals and foods eaten at weekends. Judging by comments made in focus group discussions, this appeared to be due to parents' efforts to include their children in cooking during the week and as part of a more relaxed and indulgent weekend routine.

\section{Strengths and limitations}

The present study used a variety of techniques to gather information about children's home and school food environments. This mixed-method approach not only provides a form of validation by cross-referencing responses from parents and children, but also builds up a more complete picture of the food environment, with a deeper understanding of children's motivations with regard to food choices ${ }^{(21)}$. Although focus groups can present the opportunity to pursue interesting comments and themes in depth, researcher-led focus groups may encourage children to say what they think the interviewer wants to hear ${ }^{(21)}$. This may have been an issue in the present focus groups (e.g. the emphasis on fruit and vegetables). 
The study was designed to be exploratory. Its small sample size makes it difficult to draw strong conclusions from the data and the discrepancies between focus group statements, $4 \mathrm{~d}$ food photo diaries and HFEQ responses raise questions about respondent misreporting. Linking individual parent and child data would be useful for this reason. As well as indications from some of the children that foods photographed for their $4 \mathrm{~d}$ food photo diary were dissimilar to those they would normally eat (fruit in particular), sample bias may have resulted in a higher response rate from families with healthier eating habits. More studies are needed to reinforce evidence concerning the usefulness and accuracy of such a mixed-method approach, particularly as certain aspects of these methods, such as photograph quality and corroboration of parent/child responses, need further improvement. The development of a simplified HFEQ for the child could be a plausible method to improve response accuracy.

There are many practical reasons why cameras are favoured as a data collection method for use with children - as well as being individual-focused and easy to use, they help to make participants feel valued and taken seriously ${ }^{(38)}$. While many children had trouble remembering to take pictures and struggled to remember or identify foods that they had eaten even when examining the photographs, this method received a lot of enthusiasm and positive feedback from the children and was a useful way of engaging them in the research. However, interviewing children individually about their photographs may have been advantageous as some children may have found it intimidating to discuss such personal topics in front of their peers, leading to bias in recall. The use of photographs to record food consumption allowed the foods consumed to be viewed within context, which was crucial to fulfil the study's aim of understanding children's food environments and their perspectives.

Despite the frequent appearance of siblings in photographs, no data were collected on the number of siblings children had. Knowing more about the children's home environment, such as number of siblings, would have been useful to draw more conclusions about children's perspectives. For instance, children's referral to eating alone as a treat could have been put into context if it was known whether they usually had to eat with a number of siblings and therefore appreciated solitary time.

\section{Conclusions}

The current study presents an analysis of the food environments of Year 4 pupils (8-10 years old) in Newcastle upon Tyne, UK. While the school provided a generally positive food environment, with a varied and nutritionally sound school dinner menu in accordance with current School Food Trust standards ${ }^{(16)}$, there is scope for work to tackle unhealthy packed lunch food swapping and to make the dining room a more pleasant environment, thereby encouraging the pupils' enjoyment of the food served. The children's home food environments were extremely varied and parents were shown to be key moderators of food availability and accessibility.

The children appeared to appreciate a high level of variation in what they ate (at school and at home), where they ate, and with whom they ate. Although partially explored through the HFEQ, it would be interesting to focus more emphasis on parent influence on child behaviours, in order to determine the key driving factors in children's food behaviours.

\section{Acknowledgements}

For the period of the present work, A.A.L. was funded by NIHR (National Institute for Health Research) Personal Awards at Newcastle University. The views expressed in this publication are those of the authors and not necessarily those of the National Health Service, NIHR or Department of Health. The authors declare that they have no competing interests. L.B. was responsible for conducting observations at the school, collecting and analysing the data, and writing the manuscript. A.A.L. designed the study, led focus groups with the children and gave direction across all stages of the project. Both authors contributed to all drafts of this paper. The authors thank the school, children and parents who took part in the study; Dr Angela Jones, Human Nutrition Research Centre (HNRC), Newcastle University, for reviewing early versions of this paper; and Professor Ashley Adamson, HNRC, Newcastle University, for her support and advice. This paper is dedicated to the memory of David FU Ashwell.

\section{References}

1. The NHS Information Centre LS (2009) National Child Measurement Programme: England, 2008/09 School Year. London: Department of Health, Department for Children, Schools \& Familes.

2. Lake AA, Mathers JC, Rugg-Gunn AJ et al. (2006) Longitudinal change in food habits between adolescence (11-12 years) and adulthood (32-33 years): the ASH30 Study. J Public Health 28, 10-16.

3. Lake AA, Adamson AJ, Craigie AM et al. (2009) Tracking of dietary intake and factors associated with dietary change from early adolescence to adulthood: the ASH30 Study. Obes Facts 2, 157-165.

4. Lake A \& Townshend T (2006) Obesogenic environments: exploring the built and food environments. J R Soc Promot Health 126, 262-267.

5. Townshend T \& Lake AA (2009) Obesogenic urban form: theory, policy and practice. Health Place 15, 909-916.

6. van der Horst K, Timperio A, Crawford D et al. (2008) The school food environment: associations with adolescent soft drink and snack consumption. Am J Prev Med 35, 217-223.

7. Burgoine T, Lake AA, Stamp E et al. (2009) Changing foodscapes 1980-2000, using the ASH30 Study. Appetite 53, $157-165$. 
8. Story M, Kaphingst K, Robinson-O'Brien R et al. (2008) Creating healthy food and eating environments: policy and environmental approaches. Annu Rev Public Health 29, 253-272.

9. Bryant M \& Stevens J (2006) Measurement of food availability in the home. Nutr Rev 64, 67-76.

10. Rosenkranz RR \& Dzewaltowski DA (2008) Model of the home food environment pertaining to childhood obesity. Nutr Rev 66, 123-140.

11. Gattshall M, Shoup J, Marshall J et al. (2008) Validation of a survey instrument to assess home environments for physical activity and healthy eating in overweight children. Int J Behav Nutr Phys Act 5, 3.

12. Campbell K, Crawford D, Salmon J et al. (2007) Associations between the home food environment and obesitypromoting eating behaviors in adolescence. Obesity (Silver Spring) 15, 719-730.

13. Bryant M, Ward D, Hales D et al. (2008) Reliability and validity of the Healthy Home Survey: a tool to measure factors within homes hypothesized to relate to overweight in children. Int J Behav Nutr Phys Act 5, 23.

14. Vereecken C, Huybrechts I, Maes L et al. (2008) Food consumption among preschoolers. Does the school make a difference? Appetite 51, 723-726.

15. Carter M-A \& Swinburn B (2004) Measuring the 'obesogenic' food environment in New Zealand primary schools. Health Promot Int 19, 15-20.

16. School Food Trust (2007) School Food Trust Guidelines. http://www.schoolfoodtrust.org.uk/the-standards/the-foodbased-standards/final-food-based-standards-for-school-lunches (accessed August 2011).

17. Gosling R, Stanistreet D \& Swami V (2008) 'If Michael Owen drinks it, why can't I?' - 9 and 10 year olds' perceptions of physical activity and healthy eating. Health Educ J 67, 167-181.

18. Lazarou C (2008) The influence of parents' dietary beliefs and behaviours on children's dietary beliefs and behaviours. The CYKIDS study. Appetite 51, 690-696.

19. Newcastle City Council (2009) Local Information about Ouseburn. Newcastle: Newcastle City Council.

20. Noble M, McLennan D, Wilkinson K et al. (2008) The English Indices of Deprivation 2007: Summary. London: Department for Communities and Local Government.

21. Pearce A, Kirk C, Cummins S et al. (2009) Gaining children's perspectives: a multiple method approach to explore environmental influences on healthy eating and physical activity. Health Place 15, 614-621.

22. Parkinson K, Wright C \& Drewett R (2007) The Gateshead Millennium Baby Study: a prospective study of feeding and growth. Int J Soc Res Methodol 10, 335-347.
23. Fade S (2003) Communicating and judging the quality of qualitative research: the need for a new language. $J$ Hum Nutr Diet 16, 139-149.

24. Gregory S (1995) Using qualitative research for the sociology of food. Br Food J 97, 32-35.

25. Lake AA, Hyland RM, Rugg-Gunn A et al. (2009) Combining social and nutritional perspectives: from adolescence to adulthood (The ASH30 Study). Br Food J 111, 1200-1211.

26. Lake AA, Tyrrell RL, Greenhalgh F et al. (2009) Measures of the food environment of young adults: linking individual behaviour to the environmental context. Presented at the 7 th International Conference on Diet and Activity Methods, Washington, DC, 5-7 June 2009, p. 56; available at http/www. icdam.org/ICDAM-Program_Abstracts_book.pdf

27. Krippendorff K (1980) Content Analysis: An Introduction to Its Methodology. Beverly Hills, CA: Sage.

28. Rees GA, Richards CJ \& Gregory J (2008) Food and nutrient intakes of primary school children: a comparison of school meals and packed lunches. J Hum Nutr Diet 21, 420-427.

29. Vereecken CA, Todd J, Roberts C et al. (2006) Television viewing behaviour and associations with food habits in different countries. Public Health Nutr 9, 244-250.

30. Matheson DM, Killen JD, Wang Y et al. (2004) Children's food consumption during television viewing. Am J Clin Nutr 79, 1088-1094.

31. Marshall SJ, Biddle SJH, Gorely T et al. (2004) Relationships between media use, body fatness and physical activity in children and youth: a meta-analysis. Int J Obes Relat Metab Disord 28, 1238-1246.

32. Jackson DM, Djafarian K, Stewart J et al. (2009) Increased television viewing is associated with elevated body fatness but not with lower total energy expenditure in children. Am J Clin Nutr 89, 1031-1036.

33. Murcott A (1997) The lost supper. Times Higher Education Supplement 1265, 15.

34. Styles B (2008) Moving on from free school meals: national census data can describe the socio-economic background of the intake of each school in England. Educ Res 50, $41-53$.

35. Hupkens CLH, Knibbe RA, van Otterloo AH et al. (1998) Class differences in the food rules mothers impose on their children: a cross-national study. Soc Sci Med 47, 1331-1339.

36. Anderson AS \& Morris SE (2000) Changing fortunes: changing food choices. Nutr Food Sci 30, 12.

37. Furst T, Connors M, Bisogni JS et al. (1996) Food choice: a conceptual model of the process. Appetite 26, 247-266.

38. Dennis S Jr, Gaulocher S \& Carpiano R (2009) Participatory Photo Mapping (PPM): exploring an integrated method for health and place research with young people. Health Place 15, 466-473. 